\title{
El derecho fundamental a la buena administración y el Derecho administrativo
}

rdai.com.br/index.php/rdai/article/view/429

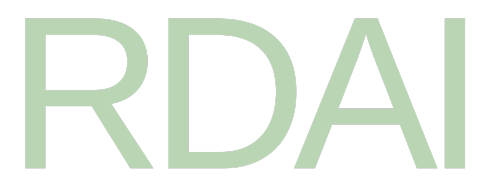

1. Início/

2. Arquivos /

3. V.5_n. 19_(2021)/

4. Doutrina Estrangeira

The Fundamental Right to Good Administration and the Science of Administrative Law

\section{Autores}

Jaime Rodríguez-Arana Muñoz Universidad de La Coruña (Coruña, Galicia, España)

\section{DOI:}

https://doi.org/10.48143/rdai.19.jram

\section{Palavras-chave:}

Administración pública, Derecho fundamental, Interés general

\section{Resumo}

El derecho administrativo tiene la obligación de mejorar la calidad de vida de la población y, en lugar de los privilegios, de la autoridad y prerrogativas del administrador, el Estado social y democrático de Derecho cobra importancia la buena administración a favor del ciudadano como participante efectivo. Los intereses generales articulan el derecho a la buena administración como derecho fundamental del individuo a través de una acción dinámica, propia del Estado social democrático de derecho en busca del equilibrio entre poder y libertad, en dos dimensiones importantes: conjunción con la realidad y caracterización de políticas públicas, de manera objetiva al servicio del interés general.

\section{Biografia do Autor}

Jaime Rodríguez-Arana Muñoz, Universidad de La Coruña (Coruña, Galicia, España) 
Profesor de la Universidad de La Coruña (Galicia, España). Catedrático-director del grupo de investigación de derecho público global. Presidente del Foro Iberoamericano de Derecho Administrativo.

(iD) 0000-0001-9641-5419. | rajaime@gmail.com

\section{Referências}

A. LÓPEZ-CASTILLO. En torno a la carta de derechos fundamentales de la Unión Europea, REP, no 113, 2001, páginas 43 y siguientes.

A. WEBER. La carta de los derechos fundamentales de la Unión Europea, REDC, no 64, 2002, páginas 79 y siguientes.

T. FREIXES, Derechos fundamentales en la Unión Europea: evolución y prospectiva: la construcción de un espacio jurídico europeo de los derechos fundamentales, ReDCE, no 4, 2005, páginas 43 y siguientes.

H. FALCAO MARTINS, Administración Pública gerencial y burocracia: la persistencia entre política y administración, Revista del CLAD, no 9, 1997, páginas 1 y siguientes.

B. TOMÁS MALLÉN, El derecho fundamental a una buena Administración, INAP, Madrid, 2004.

R. ALONSO GARCIA, La carta de derechos fundamentales de la Unión Europea, Gaceta Jurídica de la Unión Europea y de la competencia, no 209, 2000, páginas 3 y siguientes.

\section{Publicado}

2021-12-15

\section{Como Citar}

MUÑOZ, J. R.-A. El derecho fundamental a la buena administración y el Derecho administrativo: The Fundamental Right to Good Administration and the Science of Administrative Law. Revista de Direito Administrativo e Infraestrutura | RDAI, São Paulo: Thomson Reuters - Livraria RT, v. 5, n. 19, p. 299-325, 2021. DOI: 10.48143/rdai.19.jram. Disponível em:

https://rdai.com.br/index.php/rdai/article/view/429. Acesso em: 7 fev. 2022.

\section{Edição}

v.5‥19_(2021).

\section{Seção}

Doutrina Estrangeira

\section{Licença}


Este trabalho está licenciado sob uma licença Creative Commons Attribution-

NonCommercial-NoDerivatives 4.0 International License.

(CC BY-NC-ND)

Este é um resumo (e não um substituto) da licença

Regras para publicaçãa

Direitrizes Editoriais

Direitos e Deveres

Errata e Retrataçãa

Preservaçãa e Plagiarismo

Revisão e Avaliação

Artigos mais lidos pelo mesmo(s) autor(es)

Jaime Rodríguez-Arana Muñoz, Sobre la naturaleza jurídica de los aeropuertos privados internacionales,$\underline{\text { Revista de Direito Administrativo e Infraestrutura }}$

RDAI: v.5‥17_(2021) 
